\title{
Calamia tridens variabilis ssp. n. from Kyrgyzstan (Lepidoptera, Noctuidae)
}

\author{
Peter Gyulai \\ H-3530 Miskolc, Mélyvölgy 13/A, Hungary. \\ adriennegyulai@gmail.com; https://orcid.org/0000-0003-3878-2880
}

GyulaI, P.: Calamia tridens variabilis ssp. n. from Kyrgyzstan (Lepidoptera, Noctuidae).

Abstract: Description of a new subspecies of Calamia tridens (Hufnagel, 1766), with six colour imagines and seven genitalia figures are given.

Keywords: Noctuidae, Kyrgyzstan, taxonomy, new description

\section{Introduction}

Calamia (Hübner, 1821) is a small genus of Noctuidae, its taxonomy see ZILLI at al. 2005. The most widely distributed species of the genus, is the C. tridens (Hufnagel, 1766), with some described synonyms (ZILLI at al. 2005) and forms (WARREN, in SEITZ 1910-1914); its range covers most parts of the western Palaearctic, SW Siberia and north western Central Asia. Its southern sister - species is the anatolian-iranian C. staudingeri Warnecke, 1941; however, due to the very resembling external and genitalia features, their exact distribution pattern in western Asia is not known; the dissected ones by the author from Kazakhstan and Kyrgystan proved to C. tridens. The forewing ground colour of these two species is green, which becomes to faded or pale yellowish over time. The three further species being associated to this genus, have red-brown (C. metamorpha Boursin, 1960 in iranian Baluchistan and C. deliciosa Boursin, 1957 in Tajikistan and Afghanistan) forewings, while those are fuscous-greyish with whittish wing pattern in C. decipiens (Alphéraky, 1895) (S Siberia, E Kazakhstan, NW China, Mongolia).

Surprisingly, dissecting brown-forewinged Noctuidae from Kyrgyzstan, Tian-Shan Mts., Suusamyr, author recognized, that the genitalia of these specimens almost overlap with those of the true $C$. tridens. Furthermore, a few specimens were also found with greenish shaded forewings, but with the same wing pattern and locality. Although the external features of the specimens of this local population are very dissimilar from the $C$. tridens, the male and female genitalia definitely resembling to that of $C$. tridens. Thus, this population is described here below as the subspecies of $C$. tridens.

Abbreviations for personal and institutional collections used herein include: $\mathrm{HNHM}=$ Hungarian Natural History Museum (Budapest, Hungary); PGYM = collection of Péter Gyulai (Miskolc, Hungary); GYP = genitalia slide of Péter Gyulai; HT = holotype; PT $=$ paratype; male $=$ male; $\mathrm{f}=$ female. 


\section{Description of new taxa}

Calamia tridens variabilis ssp. $\mathrm{n}$.

(Figs $1-5,7,8,10,12$ )

Holotype: Male (Fig. 1), Kyrgyzstan, Tjan-Shan Mts., Suusamyr too, prope pag, Kyzyl-Oj, 1800 m, 31. VII. 2000, lum., E. Rutjan leg., slide no. GYP 1355 (coll. PGYM, later to be deposited in the HNHM).

Paratypes: 4 males, 1 female, with same data; 1 male, 1 female, Kyrgyzstan, Inner Tjan-Shan Mts., Suusamyr Mts., Kyzyl-Oj vill. circ., 1900 m, 1. VIII. 2000, I. Pljushtch leg. (coll. PGYM); 1 male, Kyrgyzstan, Inner Tjan-Shan Mts., Suusamyr Mts., E part, 2900 m, 29. VII. 2000, I. Pljushtch leg. (coll. PGYM).

slide nos. GYP 1410m, 5430m, 5431f, $5438 \mathrm{f}$

Diagnosis. The specimens of new subspecies (Figs. 1-5) are larger than those of the nominotypical form (Fig. 6); forewing length is $19-23 \mathrm{~mm}$ wingspan $39-45 \mathrm{~mm}$, versus $16-20 \mathrm{~mm}$ and 33-42 $\mathrm{mm}$. It differs in the brown or greenish shaded ground colour of forewings, always with the presence of the typical Noctuidae wing pattern and darker hindwings; while in the nominotypical form the forewings always unicolorous green, faded-greenish and lack the wing pattern, or only the reniform stigmata are marked with a small, usually whitish, rarely pinkish spot.

In the male genitalia (Figs. 7, 8), the new subspecies have slightly broader spearshaped uncus, dorso-medial extension of juxta and less elongate apical section of the cucullus than in the nominotypical subspecies (Fig. 9); while no differences are in the vesica configuration.

In the female genitalia (Figs. 10, 12), the most conspicuous differences are in the sclerotized ductus bursae. It is thinner, evenly tubular and more ribbed longitudinally in the new subspecies, while much broader and asymmetrical in the nominotypical subspecies (Figs. 11, 13). In the new subspecies, the corpus bursa is longer than in the typical one.

Description (Figs. 1-5). Forewing length 19-23 mm. wingspan 39-45 mm. Vesture of body and ground colour of forewings very variable; brown, greenish, faded greenishyellowish, but always with the same, defined wing pattern. Transverse lines brown with lighter ghost, or whitish in the greenish specimens; antemedian line wavy, postmedian line evenly arcuate and lacy, subterminal line light, finely sinuous, with more or less small wedge-like spots in the inner side; cilia brown, pinkish brown. Orbicular spot faint, reniform stigma typical, light brownish or whitish, claviform spot absent. Hindwings whitish, more or less light brown suffused, particularly in the marginal area; the main veins well defined, brown, discal spot a fine arch or absent; fringe whitish.

Male genitalia (Figs. 7, 8). The most remarkable features are the broadly spear-shaped uncus; dorso-medial extension of the triangle juxta; U-shaped vinculum; large ampulla with hammer-like terminal extension; almost evenly broad valva with elongate triangular cucullus; ventrally curved aedeagus with a short dorsal carinal thorn; subbasally prominent vesica with a small cornutus, sitting on a small sclerotized base.

Female genitalia (Figs. 10, 12). The main characters are the followings: strongly sclerotized, distally triangular, apically pointed papillae anales; strong apophyses anteriores and longer but thinner apophyses posteriores; sclerotized, broadly V-shaped antrum, of which the plate with slight, strongly sclerotized, bilateral, symmetrical lobi; tubular, sclerotized, longitudinally wrinkled ductus bursae; membranous appendix bursae and corpus bursae, from which the former one small, the latter one saccate, long. 


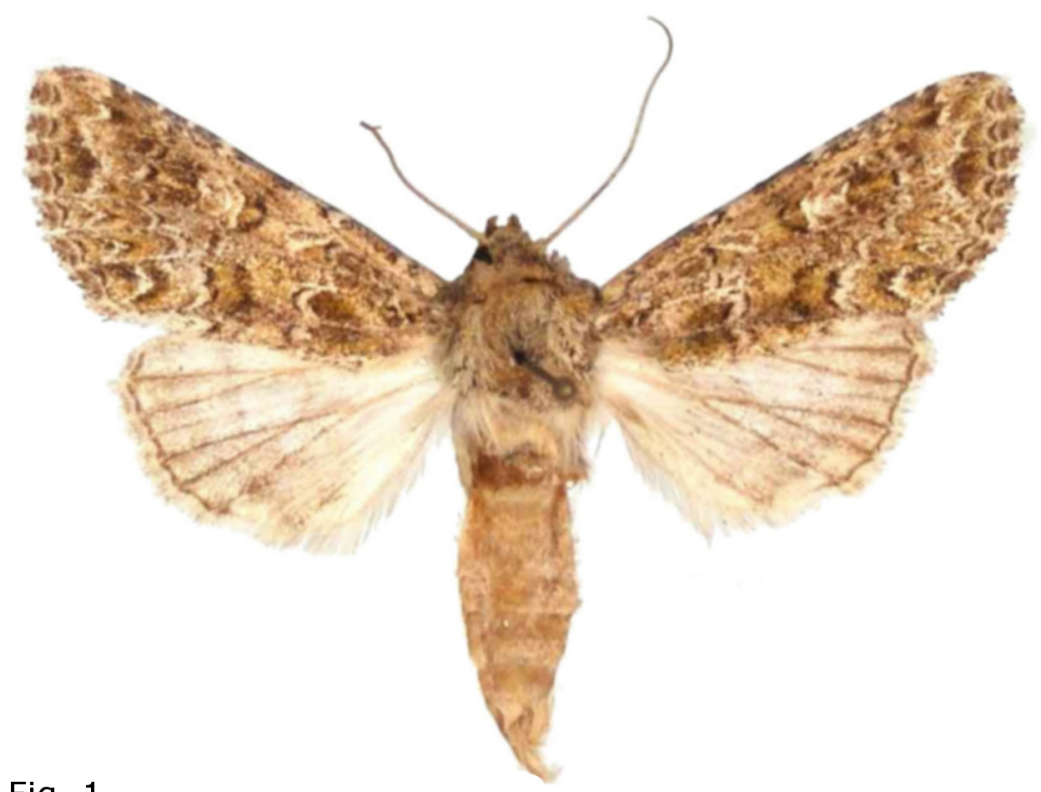

Fig. 1 .

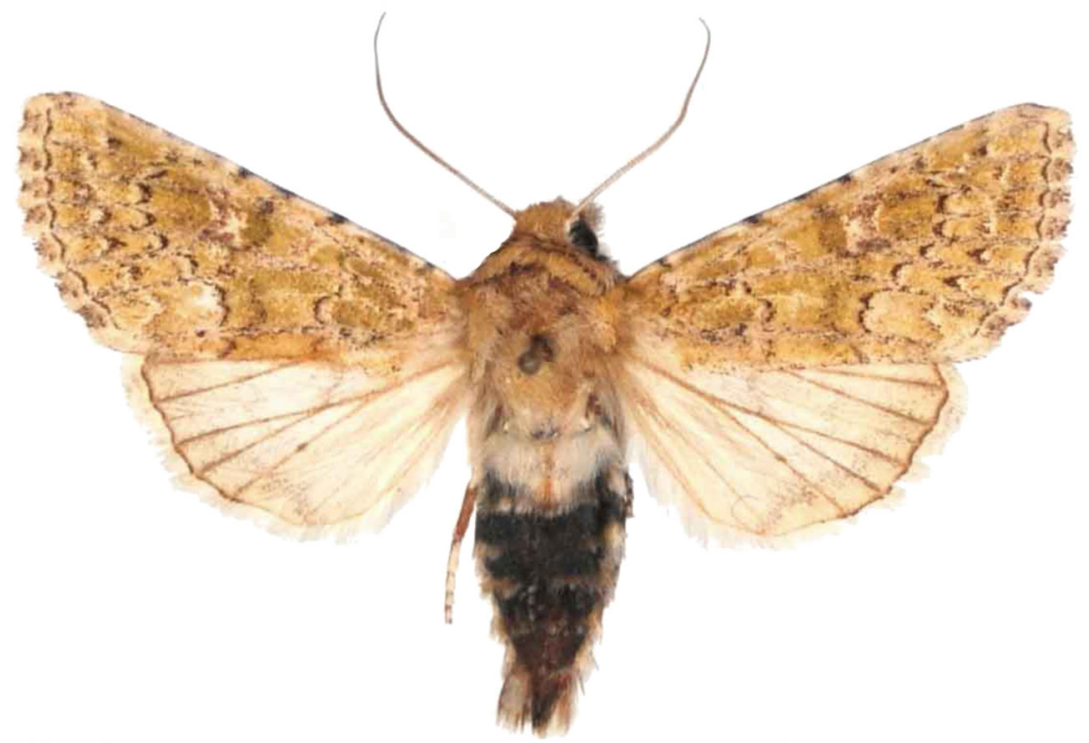

Fig. 2 .

Figures 1-2: Calamia spp. adults. 1. C. tridens variabilis ssp. n. male, HT, Kyrgyzstan, TianShan Mts., Suusamyr too, prope pag, Kyzyl-Oj, 1800 m, 31. VII. 2000, lum., E. Rutjan leg., GYP 1355 (coll. PGYM); 2. C. tridens variabilis ssp. n. male, PT, Kyrgyzstan, Tian-Shan Mts., Suusamyr too, prope pag, Kyzyl-Oj, 1800 m, 31. VII. 2000, lum., E. Rutjan leg. (coll. PGYM). 


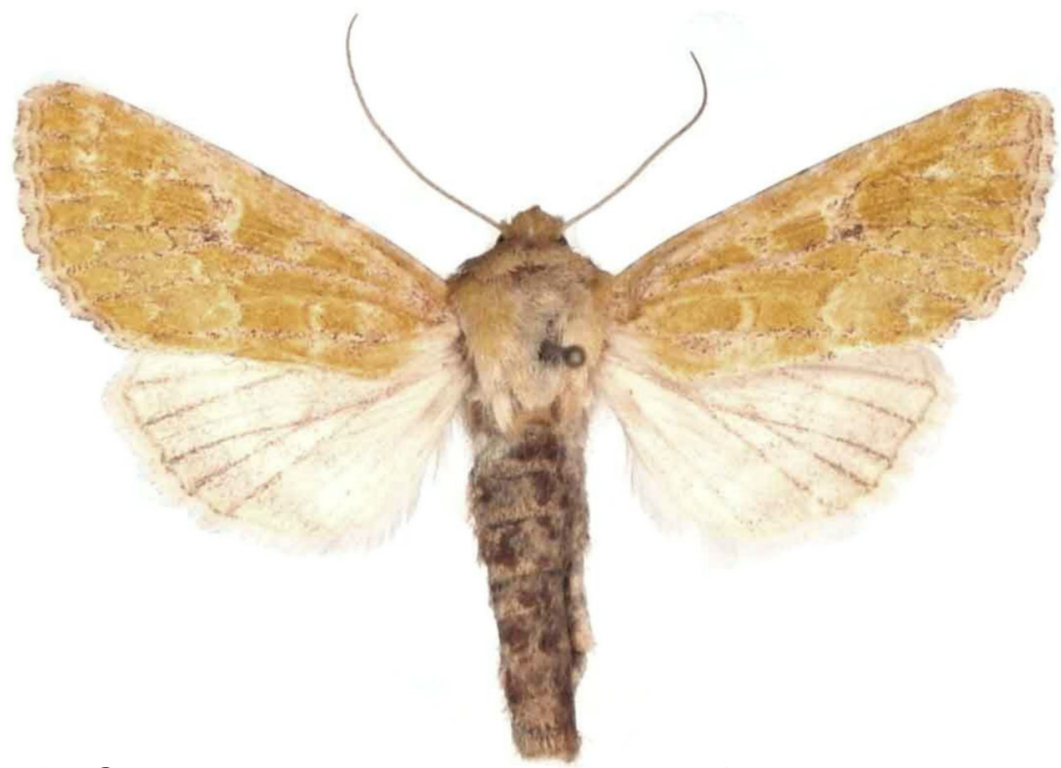

Fig. 3.

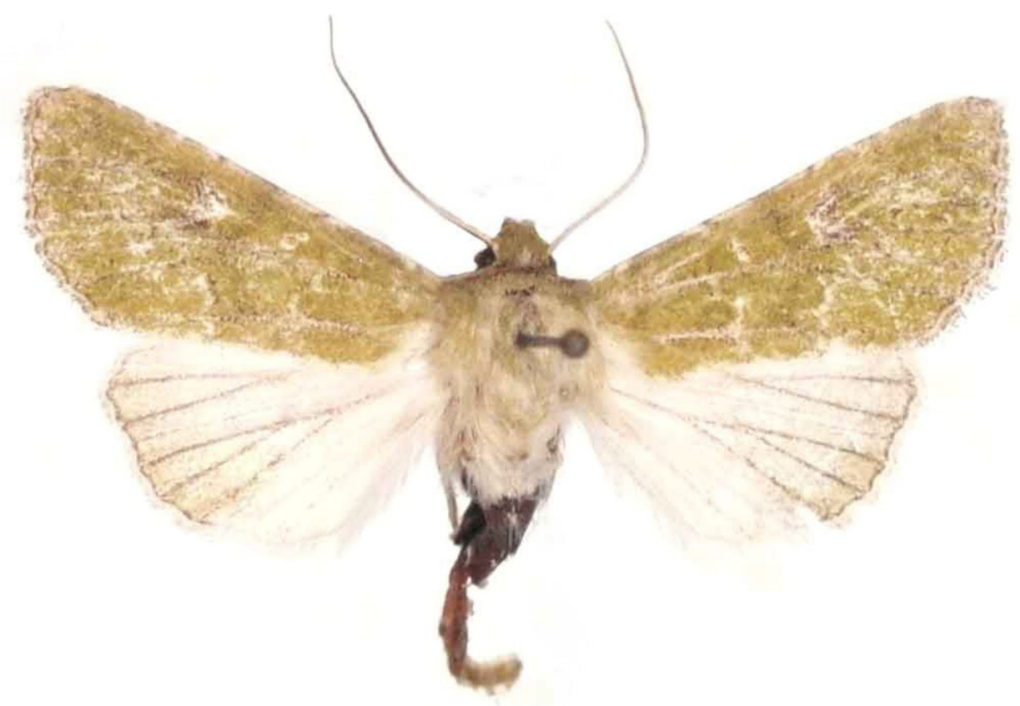

Fig. 4.

Figures 3-4:Calamia spp. adults. 3. C. tridens variabilis ssp. n. female, PT, Kyrgyzstan, TianShan Mts., Suusamyr too, prope pag, Kyzyl-Oj, 1800 m, 31. VII. 2000, lum., E. Rutjan leg., GYP 5438 (coll. PGYM); 4. C. tridens variabilis ssp. n. male, PT, Kyrgyzstan, Inner Tian-Shan Mts., Suusamyr Mts., (E part), Kyrgyz pass, 2900 m, 29. VII. 2000, Pljushtch leg., GYP 1410 (coll. PGYM). 


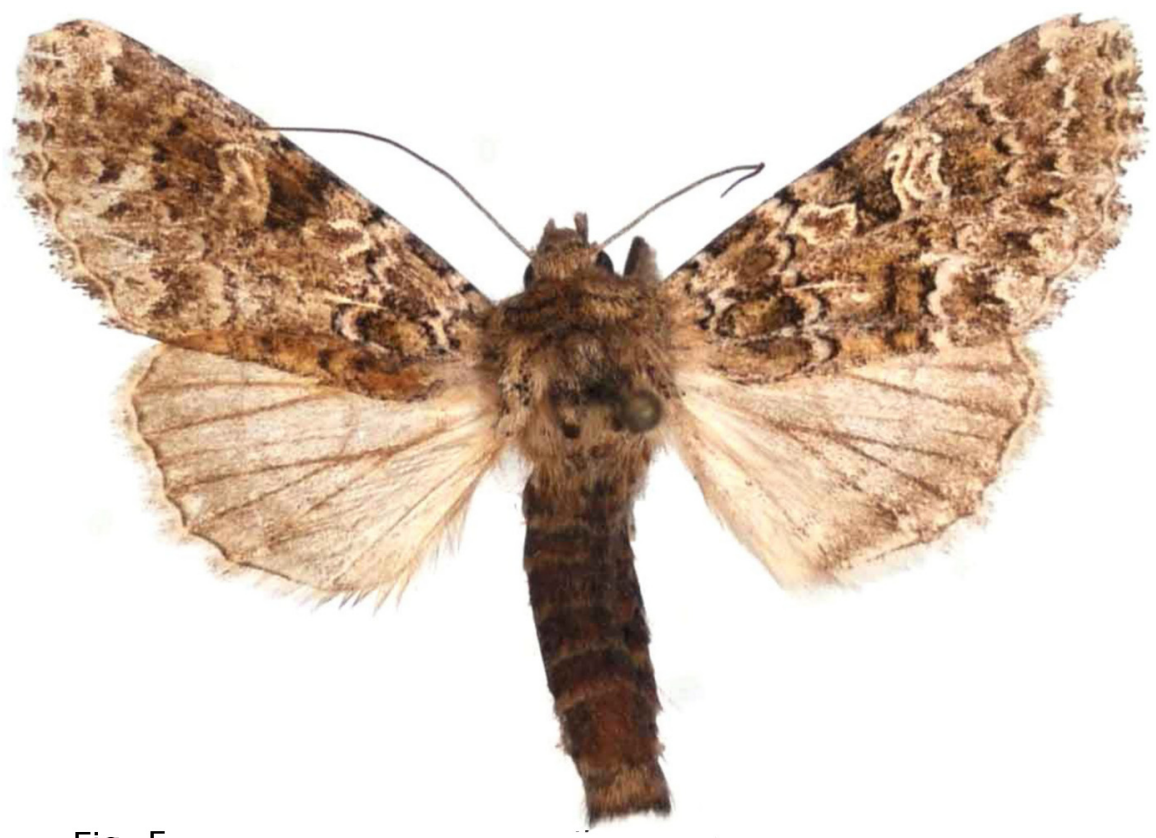

Fig. 5 .

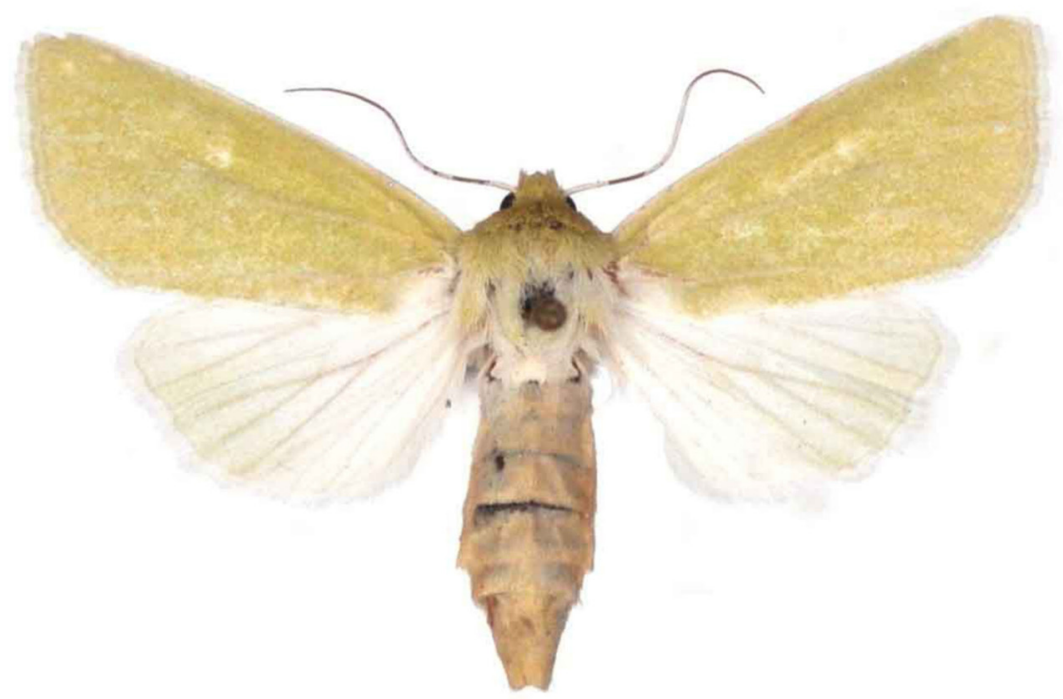

Fig. 6.

Figures 5-6: Calamia spp. adults. 5. C. tridens variabilis ssp. n. female, PT, Kyrgyzstan, Inner Tjan-Shan Mts., Suusamyr Mts., Kyzyl-Oj vill. circ., 1900 m, 1. VIII. 2000, I. Pljushtch leg., GYP 5431 (coll. PGYM); 6. C. tridens (Hufnagel, 1766), female, Hungary, Bükk Mts., Kisgyőr, 4. VIII. 1977, P. Gyulai leg. (coll. PGYM). 


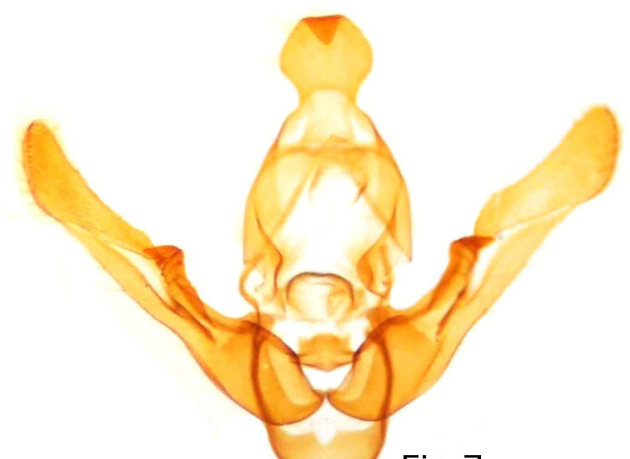

Fig 7.

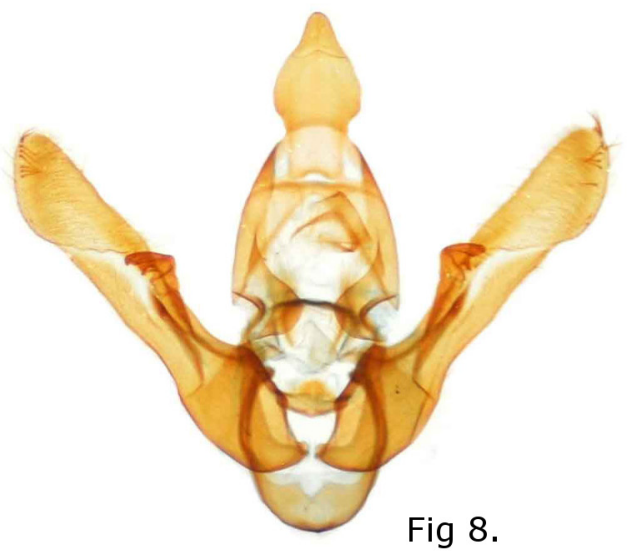

Fig 8.
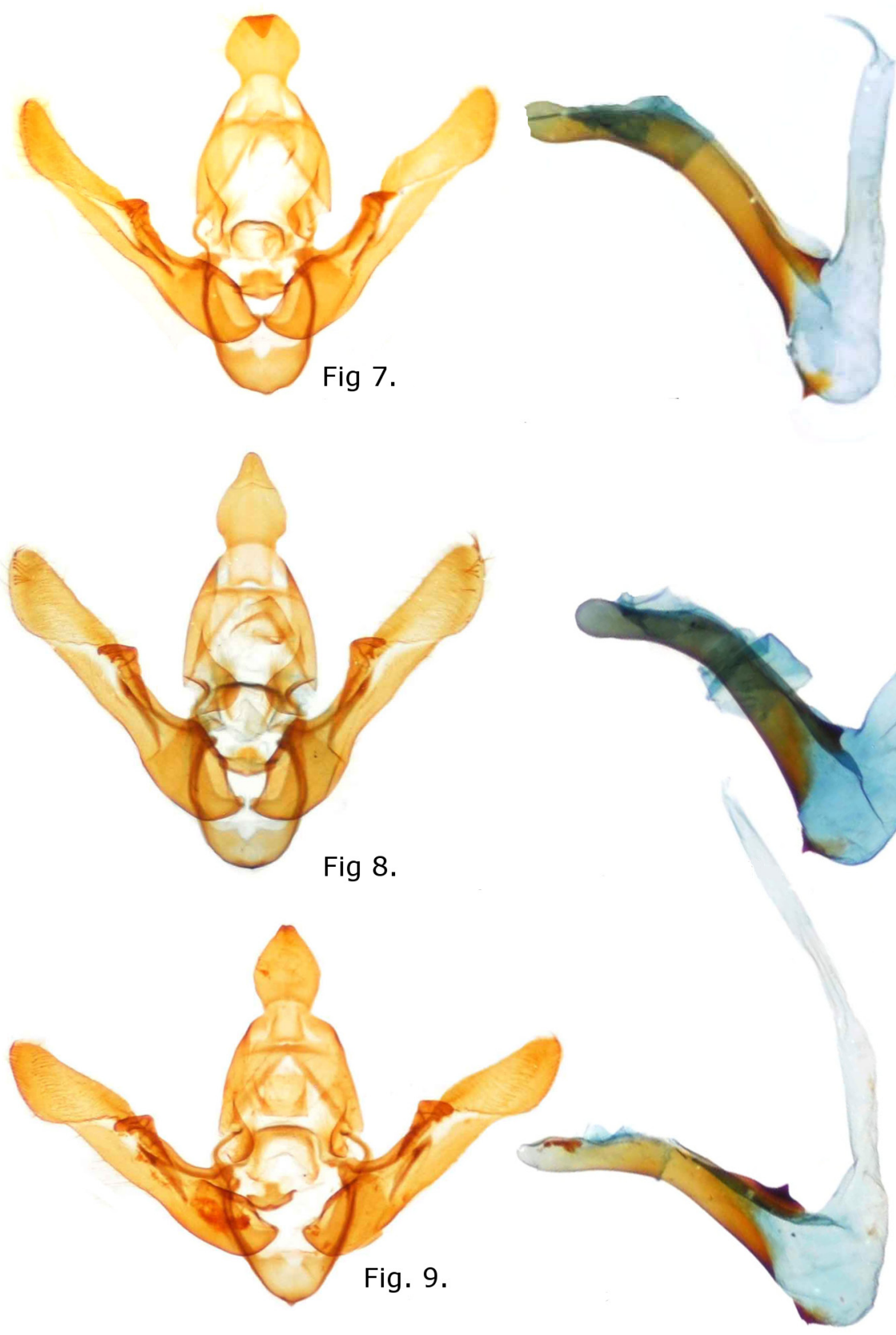

Figures 7-9: Calamia spp. male genitalia. 7. C. tridens variabilis ssp. n. HT, Kyrgyzstan, GYP 1355 (coll. PGYM); 8. C. tridens variabilis ssp. n. PT, Kyrgyzstan, GYP 1410 (coll. PGYM); 9. C. tridens (Hufnagel, 1766), Hungary, Nyékládháza, GYP 5435 (coll. PGYM). 


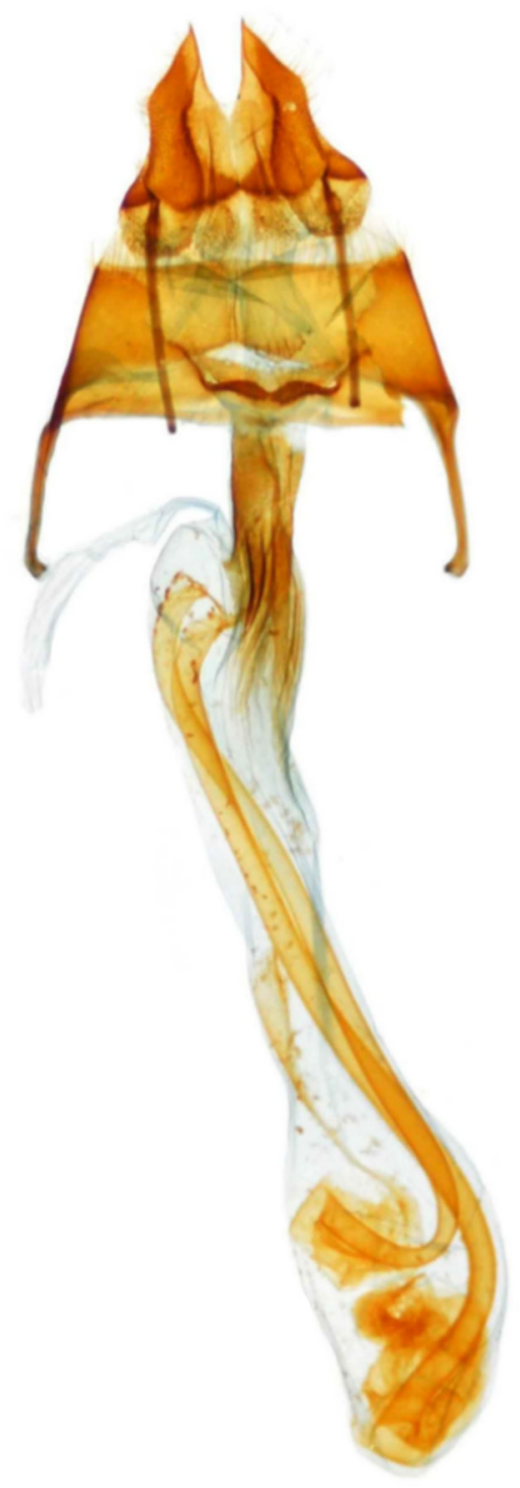

Fig. 10.

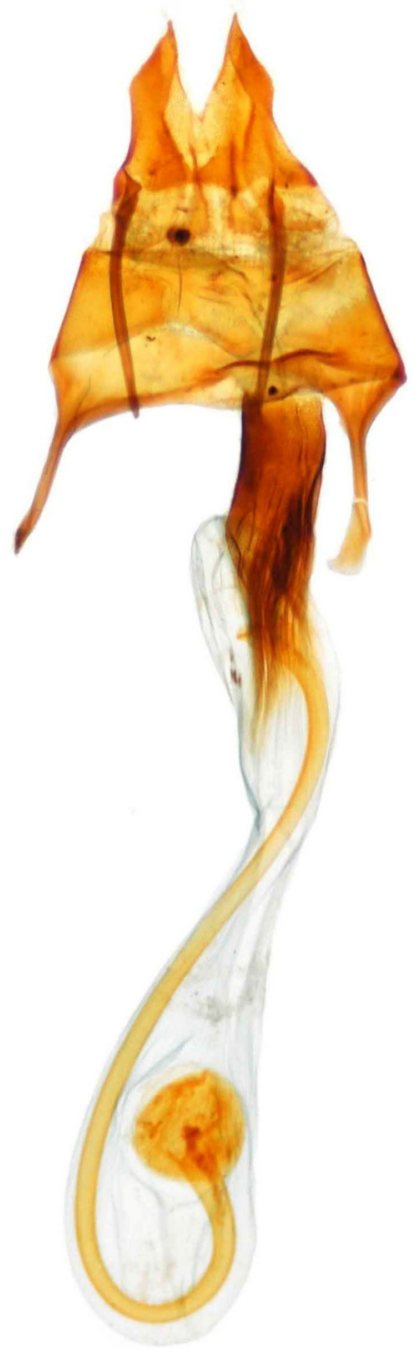

Fig. 11.

Figures 10-11: Calamia spp. female genitalia. 10. C. tridens variabilis ssp. n. PT, Kyrgyzstan, GYP 5431 (coll. PGYM); 11. C. tridens (Hufnagel, 1766), Hungary, Nyékládháza, GYP 5429 (coll. PGYM). 


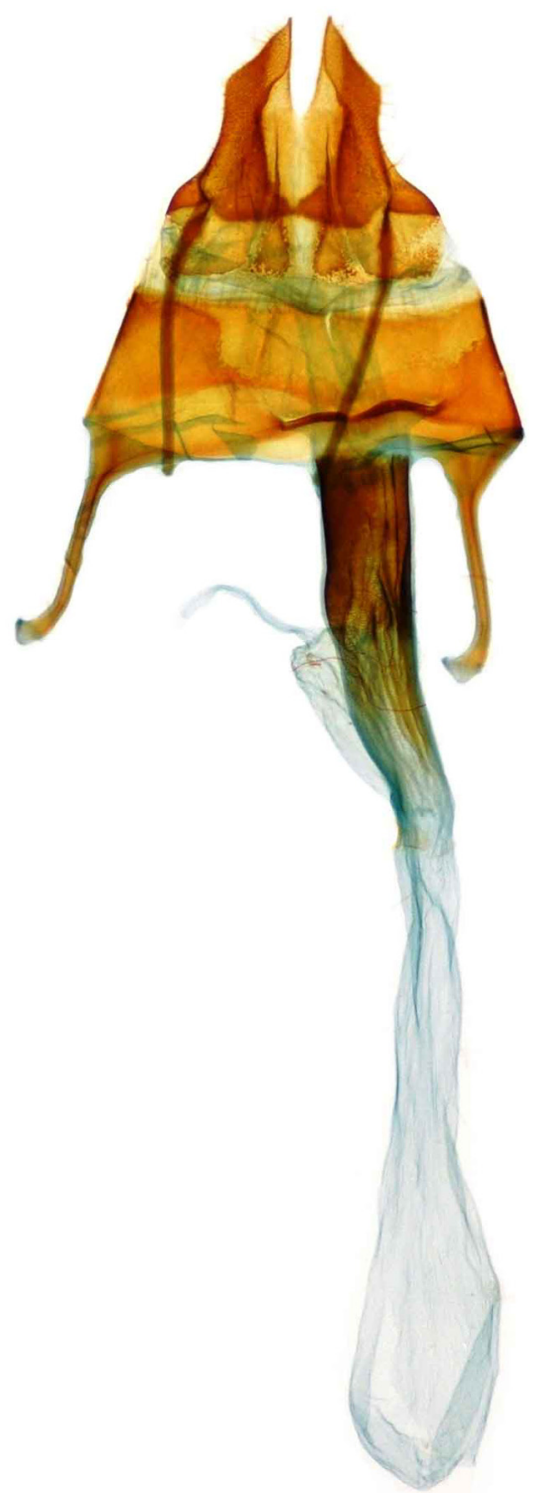

Fig. 12 .

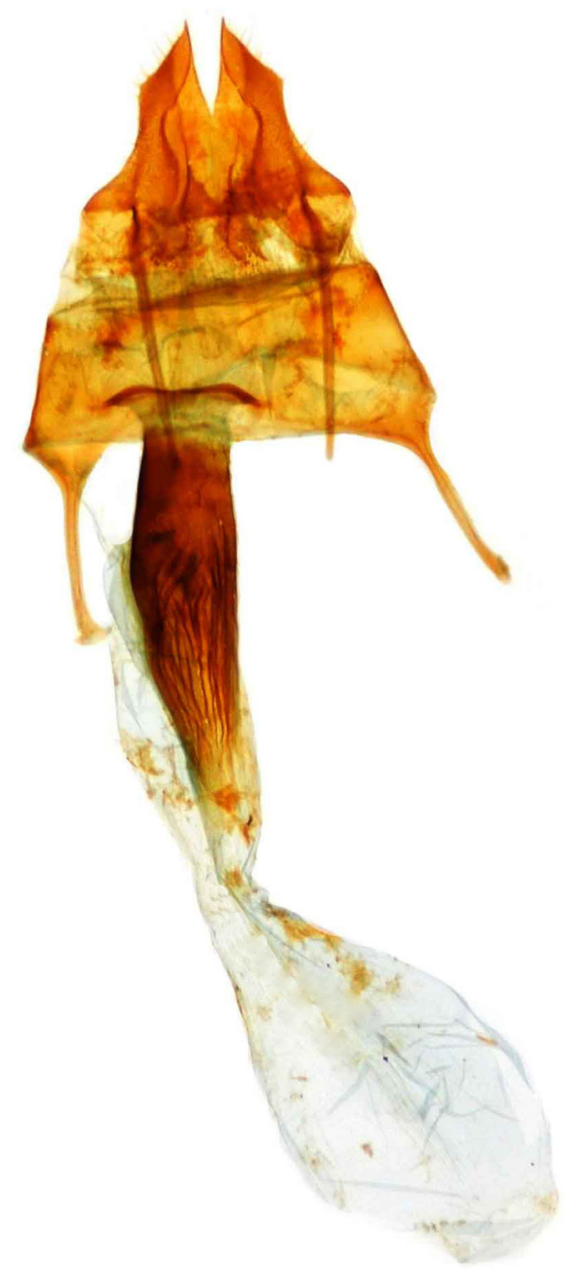

Fig 13.

Figures 12-13: Calamia spp. female genitalia. 12. C. tridens variabilis ssp. n. PT, Kyrgyzstan, Tian-Shan Mts., GYP 5438 (coll. PGYM); 13. C. tridens (Hufnagel, 1766), Kazakhstan, Altay, GYP 5436 (coll. PGYM). 
Bionomics and distribution: The type series is known from the Suusamyr Mts.; however two specimens have been seen from two, relative close localities.

Etymology. The name of the new subspecies refers to its significant external variability.

\section{Acknowledgements}

The author is grateful to his wife, Adrienne Gyulai-Garai (Miskolc, Hungary) for much help in computer works.

\section{References}

Alpheraky, S. N. 1895: Lépidoptères rapportés de la Chine et de la Mongolie par G. N. Potanine. - Mémoires sur les lépidoptères St.-Pétersbourg 5: 90-123, BioStor: 71082

Boursin, CH. 1957: Nouvelles „Trifinae” d'Afghanistan de l'expedition Klapperich (Lep. Noctuidae) (Diagnoses préliminaires). - Bulletin Mensuel de la Société Linnéenne de Lyon 26 (9): 242-250.

Boursin, CH. 1960: Eine neue Apamea O. aus Iranisch-Belutschistan (Beiträge zur Kenntnis der „NoctuidaeTrifinae", 110). - Stuttgarter Beiträge zur Naturkunde 43: 1-3, BioStor: 233079

HÜBNER J. 1821: Verzeichniss bekannter Schmettlinge, 1816-[1826], Augsburg: bey dem Verfasser zu Finden, pp. 210, 225. https://doi.org/10.5962/bhl.title.48607

Kononenko, V. S. 2016: Noctuidae: Cuculliinae - Noctuinae, part (Lepidoptera). - Noctuidae Sibiricae. Part 3. - Museum Witt Munich 5: 1-497 (3), Munich - Vilnius.

Warnecke, G. 1941: Über Calamia (Luceria) virens L. und ihre "Form" immaculata Stgr. - Zeitschrift der Österreichischer Entomologisches Vereins 26: 99-104

Warren, W. 1910-1914: Noctuidae. In Seitz, A. (Ed.), Die Gross-Schmetterlinge der Erde, III, pp. 1-496. Verlag des Seitz'schen Werkes (Alfred Kerner), Stuttgart, 31-350.

Zilli, A., Ronkay, L. \& Fibiger, M. 2005: in: Fibiger M., Apameini. Noctuidae Europaeae 8. - Sorø (Entomological Press), 309 pp. 
